\title{
IMPROVING THE ACCURACY OF THE GRAVIMETRIC METHOD FOR CONTROL PARTICULATE MATTER IN DIESEL EXHAUST
}

\section{Andrey Polivyanchuk ${ }^{1}$ \\ Igor Gritsuk ${ }^{2}$ \\ Elena Skuridina ${ }^{3}$}

DOI: https://doi.org/10.30525/978-9934-588-15-0-59

\begin{abstract}
The work is devoted to solving the actual scientific-practical problem of improving the accuracy of the gravimetric method of control of the normalized ecological index of diesel engines - average operating mass emissions of particulate matter (PM) with exhaust gases - indicator PT. Based on the analysis of requirements of regulatory documents - international standard ISO 8178, UNECE Regulations R-83, R-49, R-96 and others regarding the conditions of gravimetric measurements of this indicator, as well as the world and own experience of such measurements, the authors identified the factors that influence the accuracy of the gravimetric method of PM control and made recommendations for improving the accuracy of this method. To evaluate the effectiveness of the recommendations created a scientific - practical base for studies of the accuracy of gravimetric measurements of PM, consisting of: mathematical models for determination of temperature conditions of sampling in systems of mass emission control of PM - tunnels and the resulting error in PT measurements; experimental setup and research methodology for determining methodological error of PT measurements, which depends on the temperature conditions of sampling in the tunnel; method of estimating the significance of instrumental $\delta \mathrm{PT}_{\text {in }}$ and methodical $-\delta \mathrm{PT}$ tf components of the resulting measurement error of the indicator PT $-\delta \mathrm{PT}$. On the basis of this scientific-practical base, experimental and computational studies of the accuracy of the gravimetric
\end{abstract}

\footnotetext{
${ }^{1}$ Doctor of Technical Sciences, Professor,

O.M. Beketov National University of Urban Economy in Kharkiv, Ukraine

${ }^{2}$ Doctor of Technical Sciences, Professor,

Kherson State Maritime Academy, Ukraine

${ }^{3}$ Assistant of the Department of Urban Environmental Engineering,

O.M. Beketov National University of Urban Economy in Kharkiv, Ukraine
}

(C) Andrey Polivyanchuk, Igor Gritsuk, Elena Skuridina 
PM control method, which meets the requirements of the international standard ISO 8178, were carried out, and installed instrumental, methodological and resultant measurement errors of average operating emissions PM emission using this method: $\delta \mathrm{PT}_{\text {in }}= \pm 3.3 \ldots \pm 4.5 \% ; \delta \mathrm{PT}_{\text {tf }}=-4.5 \ldots 6.3 \%$; $\delta \mathrm{PT}=-9.0 \ldots 10.8 \%$. The effectiveness of the recommendations made by the authors is confirmed and it is established that their implementation allows to increase the accuracy of the gravimetric method of PM control in 3 times by eliminating the error $\delta \mathrm{PT}$ tf and reducing the value of $\delta \mathrm{PT}$ to the minimum level of instrumental error $\delta \mathrm{PT}_{\text {in }}= \pm 3.3 \%$.

\section{Introduction}

With the entry into force of EURO standards since 1993 to the average ecological performance of diesel engines has been introduced by the average mass emission of particulate matter (PM) with exhaust gases (EG) - an indicator of PT. According to the requirements of normative documents international standard ISO 8178, UNECE Regulations R-83, R-49, R-96 and others. this indicator is determined by the gravimetric method with the use of special equipment - tunnel in the course of the regulated test cycles.

Among the pollutants contained in EG diesel, PM occupy the second place after nitrogen oxides by the level of negative impact on the environment and are characterized by the highest relative aggressiveness (compared to carbon monoxide), equal to 200. Due to the high toxicity of PM over the last 20 years, there has been an expansion in the area of emission normalization of this substance on diesel for various purposes. Today, PM emission standards are set for diesel cars, tractors, locomotives, off-road vehicles, marine and river vessels. From 2015, the allowable emission level of PM from EG of automobile diesels is $0.005 \mathrm{~g} /(\mathrm{kWh})$, which is 72 times less than when EURO standards were introduced. At this level of emissions, the resulting measurement error of PT in the test $-\delta \mathrm{PT}$ is significant and reaches $25 \ldots 35 \%$ [1]. There is also a decrease in emissions of PM from EG other types of diesel engines. Since the accuracy of the gravimetric PM control method is a determining factor characterizing its practical applicability in determining the low emission levels PM with the exhaust gases of modern diesels, the task of creating a scientific basis and implementing practical measures to increase the sensitivity of this method is urgent. 


\section{The purpose and objectives of the research}

The purpose of this work was to improve the accuracy of the normalized gravimetric method of PM control by establishing and taking into account the factors that affect it. To achieve this goal, the following tasks were solved: 1) analysis of the gravimetric PM control method, factors that influence the measurement error of the PT index and development of recommendations for improving the accuracy of this method; 2) creation of a scientific-practical base for studies of the resulting measurement error of the PT index and its components; 3) study the accuracy of the gravimetric PM control method and evaluate the effectiveness of the recommendations made.

\section{Analysis of gravimetric method of PM control and factors that affect its accuracy}

The main components of diesel PM. Term PM means all material collected on a special filter medium from a ftoroplastic material after passing through it the diesel engine EG, diluted with atmospheric air to a temperature not exceeding $52^{\circ} \mathrm{C}$ and greater than $42^{\circ} \mathrm{C}$.

$\mathrm{PM}$ is a multicomponent formation comprising the following elements: diesel soot (product of pyrolysis of fuel), soluble organic fraction - SOF (hydrocarbon fuels and oils which are not burned and condensed and adsorbed on the surface of soot particles), sulfates (salts of sulfur)) and other inclusions (wear products, ash additives, etc.). The relative shares of these elements in the composition of PM depend on the mode of operation of the diesel and vary over wide ranges [2] (Figure 1).

Dilution systems diesel exhaust air - tunnels. To measure PM emissions from EG diesel used tunnel - pipeline, in which the diesel engine exhaust gas
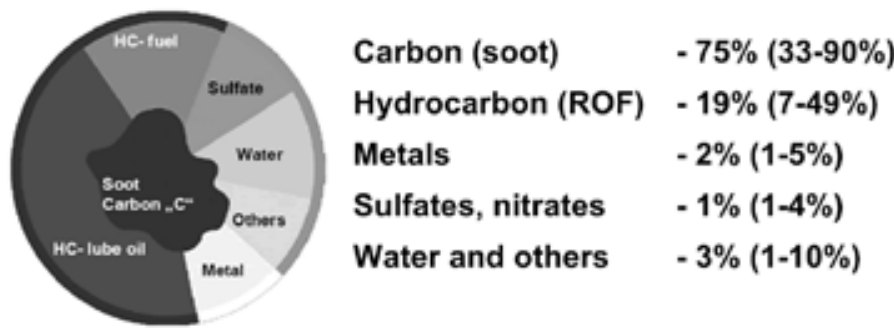

Figure 1. The components of the PM and their relative shares 
is diluted with clean air to simulate the natural process of dispersing the pollutants contained in the diesel engine in the atmosphere (Figure 2).

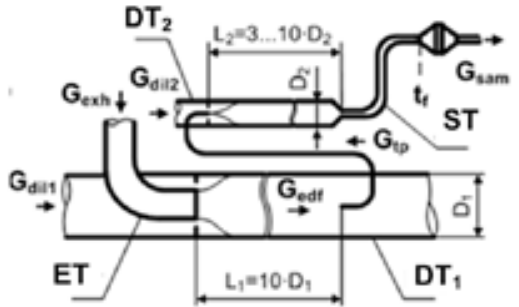

a)

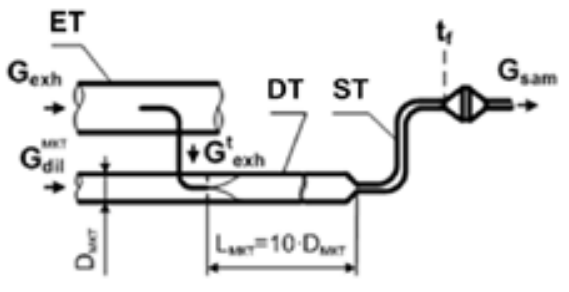

b)

Figure 2. Dilution tunnels:

a) full-flow with 2-fold dilution of EG; b) microtunnel

The reference system for PM emission control is a full-flow tunnel in which all the diesel engine exhaust air is diluted: if their mass flow rate does not exceed $750 \ldots 900 \mathrm{~kg} / \mathrm{h}$, then a 1 -fold dilution of the exhaust gas in the pipeline with a diameter $\mathrm{D} \geq 46 \mathrm{~cm}$ and a length $\mathrm{L}=10 \cdot \mathrm{D}$, otherwise - a 2-fold dilution of EG is carried out in the pipelines: primary with $\mathrm{D}_{1}=20 \ldots 46 \mathrm{~cm}, \mathrm{~L}_{1}=10 \cdot \mathrm{D}_{1}$ and secondarywith $\mathrm{D}_{2}=2,5 \ldots 10 \mathrm{~cm}, \mathrm{~L}_{2}=2,5 \ldots 10 \cdot \mathrm{D}_{2}$. The results of determining the PT value by any other measuring system must coincide with the results of the reference tunnel with a correlation coefficient of not less than 0.95 . The alternative for bulky and cost reference tunnels are compact and more affordable partial flow VH dilution systems: minitunnels and microtunnels having dimensions: $\mathrm{D}_{\mathrm{MT}}=7,5 \ldots 12 \mathrm{~cm}, \mathrm{~L}_{\mathrm{MT}}=10 \cdot \mathrm{D}_{\mathrm{MT}}$ and $\mathrm{D}_{\text {MKT }}=2,5 \ldots 4 \mathrm{~cm}, \mathrm{~L}_{\text {мКT }}=10 \cdot \mathrm{D}_{\text {MKT }}$, respectively [3; 4].

Procedures for determining average PM emissions - test cycles. Depending on the type of diesel, the average PM emission is the PT is determined during the test cycle, which consists of normalized diesel modes, characterized by: crankshaft speed $-\mathrm{n}$, load $-\mathrm{L}$, weight factor - WF. Thus, when testing motor cars, the 13-stage ESC cycle (from «European Stationary Cycle») established by UNECE Regulation R-49 is used, the agricultural diesel engine is the 8-stage cycle established by UNECE Regulation R-96 (Table 1), diesel locomotives - 3-stage cycle, established by the international standard ISO 8178, etc. 


\section{Test cycle of agricultural diesel engines}

\begin{tabular}{|c|c|c|c|}
\hline № mode & $\mathrm{n}$ & $\mathrm{L}, \%$ & WF \\
\hline 1 & \multirow{4}{*}{ nominal } & 100 & 0,15 \\
\hline 2 & & 75 & 0,15 \\
\hline 3 & & 50 & 0,15 \\
\hline 4 & & 10 & 0,1 \\
\hline 5 & \multirow{3}{*}{ intermediate } & 100 & 0,1 \\
\hline 6 & & 75 & 0,1 \\
\hline 7 & & 50 & 0,1 \\
\hline 8 & idling & - & 0,15 \\
\hline
\end{tabular}

Dilution modes of EG in tunnels. In accordance with the requirements of international standard ISO 8178, the following dilution modes of EG can be used in tunnels. DM1 - CVS mode (from "Constant Volume Sampling"), in which the mass flow of diluted EG in the tunnel is maintained constant throughout the cycle; DM2 - a mode with a constant value of the dilution factor EG; when using this mode the concentrations of PM in the diluted EG increase, which allows to increase the accuracy of their determination.

Calculation of mass and mid- average PM emissions. Mass PM emissions with diesel exhaust at separate test modes $-\mathrm{PT}_{\text {massi }}$ are determined by the formula:

$$
P T_{\text {massi }}=\frac{m_{f i}}{m_{\text {sami }}} \cdot \frac{G_{\text {edfi }}}{1000}, \mathrm{~g} / \mathrm{h} ;
$$

where $\mathrm{m}_{\mathrm{fi}}$ - the mass of PM on the filter collected on the i-th mode, mg; $\mathrm{m}_{\text {sami }}$ - the mass of the diluted EG sample passed through the mode filter, $\mathrm{kg}$;

$\mathrm{G}_{\text {edi }}$ - equivalent mass flow of diluted $\mathrm{EG}$ in the ith mode (equal to the mass flow rate of the diluted EG in the reference system), $\mathrm{kg} / \mathrm{h}$ :

$$
G_{\text {edf } i}=G_{\text {exhi }} \cdot q_{i},
$$

where $q_{i}$ - the dilution factor of EG in the i-th mode;

$\mathrm{G}_{\text {exhi }}$ - the mass flow rate of diesel exhaust at the $\mathrm{i}$-th mode, $\mathrm{kg} / \mathrm{h}$.

The average PM emission with diesel exhaust gas - PT is defined as the ratio of the average for the $\mathrm{PM}$ mass cycle $-\mathrm{PT}_{\text {mass }}$ and the effective diesel power $-\mathrm{P}_{\mathrm{m}}$ : 


$$
P T=\frac{P T_{\text {mass }}}{P_{m}}, \mathrm{~g} / \mathrm{kWh},
$$

The value of $\mathrm{PT}_{\text {mass }}$ is calculated by the formula

$$
P T_{\text {mass }}=\frac{m_{f}}{m_{\text {sam }}} \cdot \frac{G_{\text {edf }(m)}}{1000}, \mathrm{~g} / \mathrm{h},
$$

where $\mathrm{m}_{\mathrm{f}}$ - the mass of PM collected on the filter per cycle, $\mathrm{mg}$;

$\mathrm{m}_{\text {sam }}$ - the mass of the diluted EG sample that has passed through the filter over the cycle, provided that the values of $\mathrm{m}_{\text {sami }}$ are proportional to the respective weighting factors $-\mathrm{WF}_{\mathrm{i}}$ (at 2-fold dilution of $\mathrm{EG} \mathrm{m}_{\mathrm{sam}}=\mathrm{m}_{\mathrm{sam} 2}-$ $\mathrm{m}_{\text {dil2 }}$, where $\mathrm{m}_{\text {sam2 } 2}, \mathrm{~m}_{\text {dil2 }}$ - the masses of diluted EG and air, passed through the filter during the cycle), $\mathrm{kg}$;

$\mathrm{G}_{\text {edf(m) }}$ - the average equivalent mass flow rate of diluted EG in the tunnel, $\mathrm{kg} / \mathrm{h}$.

The values included in formula (2) are defined as follows:

$$
m_{\text {sam }}=\sum_{i=1}^{n} m_{\text {sami }}
$$

where $\mathrm{n}-$ the number of modes in cycles;

$$
G_{e d(m) f}=\sum_{i=1}^{n} W F_{i} \cdot G_{e d f i}, \mathrm{~kg} / \mathrm{h} .
$$

To calculate $\mathrm{P}_{\mathrm{m}}$ use the formulas:

$$
P_{m}=\sum_{i=1}^{N}\left(P_{i} \cdot W F_{i}\right), \mathrm{kw}
$$

where $\mathrm{P}_{\mathrm{i}}$ - the effective power of the diesel engine in the $\mathrm{i}$-th mode, $\mathrm{kW}$;

$$
P_{i}=\frac{n_{i} \cdot M_{k i}}{9550}-P_{\text {auxi }}, \mathrm{kw},
$$

where $n_{i}$ - the number of revolutions of the motor shaft on the $i$-th mode, $\min ^{-1}$;

$\mathrm{M}_{\mathrm{ki}}-$ torque on the $\mathrm{i}$-th mode, $\mathrm{N} \cdot \mathrm{m}$;

$\mathrm{P}_{\text {auxi }}$ - the power of auxiliary equipment on the $\mathrm{i}$-th mode, $\mathrm{kW}$.

Factors affecting the accuracy of the gravimetric PM method. The analysis of the presented technique for determining the average PM emission shows that this indicator is indirectly measured by the results of direct measurements of $m_{f}, m_{\text {sam }}, q_{i}, G_{\text {exhi }}, n_{i}$ and $M_{k i}$. Therefore, the accuracy of determining the PT is dependent on the measurement errors of these values. 
On the other hand, the results of $\mathbf{\delta} \mathbf{M}_{\mathrm{pm}}$, experimental studies of foreign and domestic authors, presented in [5-10], indicate that the mass of the PM collected on the filter $-\mathrm{m}_{\mathrm{f}}$ depends on the temperature mode of sample preparation in the tunnel (Figure 3), which is characterized by the temperatures of diluted EG before the filter $-t_{\mathrm{fi}}$ is determined by the dilution air temperature - tilt selected maximum sample temperature in the tunnel $\mathrm{t}_{\mathrm{f}(\max )}$. Variation of $\mathrm{t}_{\mathrm{dil}}$ values $\mathrm{t}_{\mathrm{f}(\max )}$ in the admissible regulatory documents ranges $\mathrm{t}_{\mathrm{dil}}=25 \pm 5^{\circ} \mathrm{C}$ and $\mathrm{t}_{\mathrm{f}(\max )}=42-52^{\circ} \mathrm{C}$ leads to a methodological error in the measurement

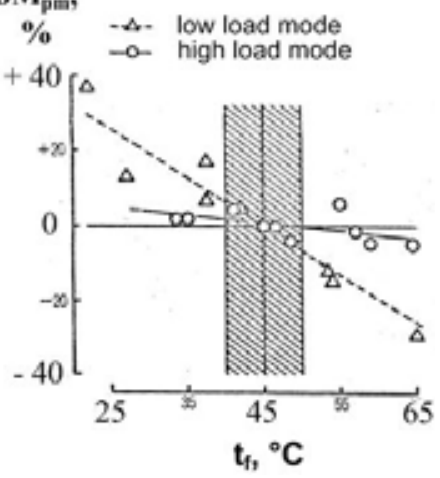

Figure 3. Experimental data on the effect of temperature tf on the value of $\mathrm{mf}[10]$ of the PT, which affects the accuracy of the gravimetric method of PM control.

Analysis of the experimental data presented in Fig. 3, shows that as the temperature $\mathrm{tf}$ increases, the value of $\mathrm{mf}$ decreases; however, a linear dependence can be used to describe this process:

$$
\delta m_{f}^{t f}=\frac{m_{f}^{t f}-m_{f}^{f 0}}{m_{f}^{t 0}} \cdot 100 \%=k_{t f} \cdot\left(t_{f}-t_{f 0}\right),
$$

where $\delta \mathrm{m}^{\mathrm{tf}}$ - the relative deviation of the PM weight at the sample temperature $t_{\mathrm{f}}-\mathrm{m}_{\mathrm{f}}^{\mathrm{tf}}$ from the base value $\mathrm{m}_{\mathrm{f}}^{\mathrm{tf} 0}$, which corresponds to the sample temperature $t_{\mathrm{f} 0}$, taken as the base (in the data presented in Fig. 3, $\mathrm{t}_{\mathrm{f} 0}=45^{\circ} \mathrm{C}$ );

$\mathrm{k}_{\mathrm{tf}}$ - proportionality factor, which depends on the mode of operation of the engine: as the diesel power increases, its value decreases.

Recommendations for improving the accuracy of gravimetric PM control. The analysis of the factors on which the resulting measurement error of the normalized PT indicator depends, makes the following recommendations for its reduction:

1) the use in the tunnel dilution mode EG DM2 at the minimum allowable dilution factor $E G-q_{\min }=4$, which ensures the selection of the maximum number of $\mathrm{PM}$ on the filter; 
2) elimination of methodological error of PT measurements by adjusting the temperature of the sample preparation in the tunnel, which meets the conditions of dilution of EG at $\mathrm{t}_{\mathrm{dil}}=25^{\circ} \mathrm{C}$ and $\mathrm{t}_{\mathrm{f}(\max )}=47^{\circ} \mathrm{C}$;

3 ) improving the accuracy of measurement values that are directly determined during testing and used in the calculation of the PT.

\section{Scientific-practical basis for studies of the accuracy of gravimetric control method PM \\ 4.1 Mathematical model of the process of formation of temperature conditions for PM sampling}

The mathematical model is intended to determine the main characteristic of the temperature mode of selection of PM in the tunnel - the sample temperature before the filter $-t_{\mathrm{f}}$.

In based the mathematical model is on the equation of heat balance of the process of heat exchange of heated gas in a cylindrical pipeline with ambient air (Figure 4) [11]:

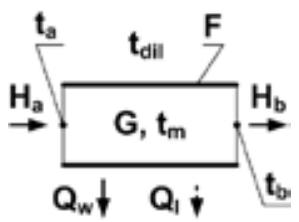

Figure 4. Calculation scheme of the heat exchange process

$$
\mathrm{H}_{a}=H_{b}+Q_{w}+Q_{l},
$$

where $\mathrm{H}_{\mathrm{a}}, \mathrm{H}_{\mathrm{b}}$ - the enthalpy of the gas stream at the inlet and outlet of the pipeline;

$\mathrm{Q}_{\mathrm{w}}$ - the heat flow transmitted through the wall of the pipeline due to heat transfer;

$\mathrm{Q}_{1}=\mathrm{r} \cdot \mathrm{H}_{\mathrm{a}}$ - thermal losses on the elements of the design of the sampling line at the flange connections and ball cranes(the proportionality factor $\mathrm{r}$ is determined experimentally by the formula $\left.\mathrm{r}=1-\left(\mathrm{H}_{\mathrm{b}}-\mathrm{Q}_{\mathrm{w}}\right) / \mathrm{H}_{\mathrm{a}}\right)$;

$$
H_{a}=c_{p} \cdot G \cdot\left(T_{a}-T_{d i l}\right) ; H_{b}=c_{p} \cdot G \cdot\left(T_{b}-T_{d i l}\right),
$$

where $c_{p}=1005 \mathrm{~J} /(\mathrm{kg} \cdot \mathrm{K})$ - the average isobaric heat capacity in the working range of the temperature variation of the working body in the tunnel; 
$\mathrm{G}$ - mass rate flow in the pipeline of the of the flow of the working body, $\mathrm{kg} / \mathrm{s}$;

$\mathrm{T}_{\mathrm{a}}, \mathrm{T}_{\mathrm{b}}$ та $\mathrm{T}_{\text {dil }}$ - respectively: absolute initial and final average mass temperature flow rates and air temperature around the pipeline, $\mathrm{K}$;

$$
Q_{w}=\left(T_{m}-T_{\text {dil }}\right) \cdot F \cdot k,
$$

where $\mathrm{T}_{\mathrm{m}}$ - the average absolute temperature of the gas flow in the tunnel (defined as the arithmetic mean of $\mathrm{T}_{\mathrm{a}}$ and $\mathrm{T}_{\mathrm{b}}$ ), $\mathrm{K}$;

$\mathrm{F}$ - the surface area of the pipeline through which heat is transmitted, $\mathrm{m}^{2}$;

$\mathrm{k}$ - heat transfer coefficient, $\mathrm{W} /\left(\mathrm{m}^{2} \cdot \mathrm{K}\right)$ :

$$
k=\frac{1}{\left(\alpha_{t}\right)^{-1}+\left(\alpha_{w c}+\alpha_{w r}\right)^{-1}}=\frac{\alpha_{t} \cdot\left(\alpha_{w c}+\alpha_{w r}\right)}{\alpha_{t}+\alpha_{w c}+\alpha_{w r}},
$$

where $\alpha_{t}$ - the heat transfer coefficient of the inner wall of the pipeline, $\mathrm{W} /\left(\mathrm{m}^{2} \cdot \mathrm{K}\right)$;

$\alpha_{\mathrm{wc}}, \alpha_{\mathrm{wr}}$ the heat transfer coefficients of the outer wall of conduit with convective and radiant heat transfer (determined by known formulas below), $\mathrm{W} /\left(\mathrm{m}^{2} \cdot \mathrm{K}\right)$.

As a result of the transformation of the heat balance equation (7), the basic calculation formula was obtained to determine the gas flow temperature at the end of the pipeline the flow of diluted $E G-t_{b}$ :

$$
t_{b}=(1-r) \cdot\left(t_{a}-t_{d i l}\right)-\frac{\left(t_{m}-t_{d i l}\right) \cdot F \cdot k}{c_{p} \cdot G}+t_{d i l},{ }^{\circ} \mathrm{C},
$$

where $\mathrm{t}_{\mathrm{a}}$ - the initial average mass temperature flow, ${ }^{\circ} \mathrm{C}$.

Since the value of $t_{m}$ at the beginning of the calculations is unknown, thats why the determination of the temperature values $t_{b}$ is carried out by the method of successive approximations. This determines the approximate value of $t_{b}$ provided $t_{m}=t_{a}$, which is refined as a result of using formula (8) until the difference between the clarification and the previous values $t_{b}$ of $t_{b}$ is less than $\pm 0.05{ }^{\circ} \mathrm{C}$ (for this is enough $3-4$ refinement calculations). The sequential calculation of the end temperatures of the gas streams in all pipelines of the dilution system EG according to the established algorithm allows to determine the sample temperature before the filter $-t_{\mathrm{f}}$.

Check the adequacy of the mathematical model was according by Fisher's criterion during the tests of the $4 \mathrm{ChN} 12 / 14$ diesel engine on the ESC cycle (Table 2) using the microtunnel MKT-2 [9; 12]. 
The results of researches of the value of tf during the tests diesel $4 \mathrm{ChN12} / 14$ with MKT-2

\begin{tabular}{|c|c|c|c|c|c|c|}
\hline $\begin{array}{c}\text { A series of } \\
\text { experiments } \\
\text { (cycle mode ESC) }\end{array}$ & $\begin{array}{l}\text { Experiment } \\
\text { number in } \\
\text { the series }\end{array}$ & $\mathbf{t}_{\mathrm{f}},{ }^{\circ} \mathbf{C}$ & $\overline{\mathbf{t}}_{\mathrm{f}},{ }^{\circ} \mathbf{C}$ & $\mathbf{t}_{\mathrm{af}},{ }^{\circ} \mathbf{C}$ & $\begin{array}{c}\mathbf{t}_{\mathbf{a f}}-\mathbf{t}_{\mathbf{f}}, \\
{ }^{\circ} \mathbf{C}\end{array}$ & $\begin{array}{c}\mathbf{t}_{\mathbf{f}}-\overline{\mathbf{t}}_{\mathbf{f}}, \\
{ }^{\circ} \mathbf{C}\end{array}$ \\
\hline \multirow{2}{*}{$\begin{array}{c}1 \\
(1)\end{array}$} & 1 & 22,2 & \multirow{2}{*}{22,1} & \multirow{2}{*}{21,88} & \multirow{2}{*}{$-0,22$} & 0,1 \\
\hline & 2 & 22,0 & & & & $-0,1$ \\
\hline \multirow{2}{*}{$\begin{array}{c}2 \\
(3) \\
\end{array}$} & 1 & 47,1 & \multirow{2}{*}{46,85} & \multirow{2}{*}{46,94} & \multirow{2}{*}{0,09} & 0,25 \\
\hline & 2 & 46,6 & & & & $-0,25$ \\
\hline \multirow{2}{*}{$\begin{array}{c}3 \\
(7) \\
\end{array}$} & 1 & 34,3 & \multirow{2}{*}{34,55} & \multirow{2}{*}{34,29} & \multirow{2}{*}{$-0,26$} & $-0,25$ \\
\hline & 2 & 34,8 & & & & 0,25 \\
\hline \multirow{2}{*}{$\begin{array}{c}4 \\
(10)\end{array}$} & 1 & 50,0 & \multirow{2}{*}{50,4} & \multirow{2}{*}{49,97} & \multirow{2}{*}{$-0,43$} & $-0,4$ \\
\hline & 2 & 50,8 & & & & 0,4 \\
\hline
\end{tabular}

Criterion F was determined by the formula:

$$
F=\frac{s_{a}^{2}}{s_{y}^{2}},
$$

where $\mathrm{s}_{\mathrm{a}}^{2}$ - the variance of model adequacy;

$\mathrm{s}_{\mathrm{y}}^{2}$ - the variance of the reproducibility of the experiment.

To determine the value of $\mathrm{s}^{2}$ used the formula that is used for uniform duplication of investigation:

$$
s_{a}^{2}=\frac{S_{a}}{f_{a}}=\frac{n \cdot \sum_{i=1}^{N}\left(t_{a f i}-\bar{t}_{f i}\right)^{2}}{N-\mathrm{p}}
$$

where $\mathrm{S}_{\mathrm{a}}$ - the sum of the squares of the deviations of the calculated and experimental data;

$f_{a}=N-p-$ the number of degrees of freedom of variance of model adequacy;

$\mathrm{n}=2$ - number of duplicate investigation in each series;

$\mathrm{N}=4$ - number of series of duplicate investigation according to the experimental plan (series of investigation were performed on 1, 3, 7 and 10 modes of the ESC cycle);

$\mathrm{i}=1 \ldots \mathrm{N}-$ the number of the series of investigation;

$t_{a f i}$ - the calculated value of the temperature $t_{f}$ for the $i$-th series;

$\bar{t}_{f}-$ average temperature $t_{f}$ for the $i$-th series; 
$p=1-$ the number of coefficients of the mathematical model determined according to experiment.

Dispersion of the reproducibility of the experiment was determined by the results of 4 duplicate experiments, as the arithmetic mean of the dispersions of these experiments:

$$
s_{y}^{2}=\frac{\sum_{i=1}^{m} s_{i}^{2}}{m}
$$

where $\mathrm{m}=4$ - the number of series of duplicate experiments;

$\mathrm{s}_{\mathrm{i}}^{2}-$ variance of reproducibility of the experiment i-th series of experiments:

$$
s_{i}^{2}=\frac{\sum_{j=1}^{n}\left(t_{i j}-\bar{t}_{i}\right)^{2}}{n-1}
$$

where $n=2$ - the number of duplicate experiments;

$t_{i j}$ - the $j$-th value of the temperature $t_{f}$ in the $i$-th series of experiments.

The number of degrees of freedom of dispersion $\mathrm{s}_{\mathrm{y}}^{2}$ for this method of determining it is $f_{y}=m \cdot(n-1)=4$.

The calculations of $\mathrm{s}^{2}, \mathrm{~s}_{\mathrm{y}}{ }_{\mathrm{y}}$ and $\mathrm{F}$ by the formulas below showed the following:

$$
\begin{gathered}
s_{a}^{2}=\frac{2 \cdot\left(0,22^{2}+0,09^{2}+0,26^{2}+0,43^{2}\right)}{4-1}=0,2063, \\
s_{y}^{2}=\frac{\left(0,1^{2}+2 \cdot 0,25^{2}+0,4^{2}\right)}{4}=0,0738, \\
F=\frac{0,2063}{0,0738}=2,85
\end{gathered}
$$

The obtained values of $\mathrm{F}$ do not exceed the critical level $-\mathrm{F}_{0,95}=5,91$, which corresponds to trust probability of 0,95 and the numbers of degrees of freedom $\mathrm{f}_{\mathrm{a}}=3, \mathrm{f}_{\mathrm{y}}=4$ [13] that confirms the adequacy of the developed mathematical model.

\subsection{Mathematical model for determining the resulting error in the meas-urement of weighted average $P M-\delta P T$}

The mathematical model allows to determine the value of $\delta \mathrm{PT}$ taking into account its instrumental $-\delta \mathrm{PT}_{\text {in }}$ and methodical $-\delta \mathrm{PT}$ tf components: 


$$
\delta P T=\delta P T_{i n}+\delta P T_{t f}
$$

The value of $\delta \mathrm{PT}_{\text {in }}$ is determined using the dependence to calculate the error of the indirect measurement result [14]:

$$
\delta y=\sqrt{\sum_{i=1}^{m}\left(\frac{\partial y}{\partial x_{i}} \cdot \frac{x_{i}}{y} \cdot \delta x_{i}\right)^{2}}
$$

where $\mathrm{y}-\mathrm{a}$ value that is measured indirectly by a known dependence $-\mathrm{y}$ $=\mathrm{f}\left(\mathrm{x}_{1}, \mathrm{x}_{2}, \ldots, \mathrm{x}_{\mathrm{m}}\right)$;

$\mathrm{x}_{\mathrm{i}}$ - the values by which it is determined $\mathrm{y}, \mathrm{m}-$ their number.

The error $\delta \mathrm{PT}_{\mathrm{tf}}$ is numerically equal to the value of $\delta \mathrm{m}_{\mathrm{f}}^{\mathrm{tf}}$ - relative deviation of the mass of the hinge $\mathrm{PM}-\mathrm{m}_{\mathrm{f}}^{\mathrm{tf}}$, determined at the actual values of the temperatures $t_{\text {fif }}$, from the mass of the hinge $P M-\mathrm{m}^{\mathrm{t} 0}{ }_{\mathrm{f}}$, determined at the values of the temperatures $\mathrm{t}_{\mathrm{f} 0 \text {, }}$, taken at the baseline and corresponding CVS-dilution of EG at $\mathrm{t}_{\mathrm{dil}}=20^{\circ} \mathrm{C}, \mathrm{t}_{\mathrm{f}(\max )}=47^{\circ} \mathrm{C}$ :

$$
\delta P T_{t f}=\delta m_{f}^{t f}=\frac{m_{f}^{t f}-m_{f}^{f 0}}{m_{f}^{f 0}} \cdot 100 \%=\sum_{i=1}^{n} \frac{m_{f i}^{t f}-m_{f i}^{f 0}}{m_{f i}^{f 0}} \cdot r_{m f i}=\sum_{i=1}^{n} \delta m_{f i}^{f f} \cdot r_{m f i},
$$

where $\delta \mathrm{m}_{\mathrm{fi}}^{\mathrm{tf}}-$ relative deviations of the mass of PM on the $\mathrm{i}-\mathrm{th}$ mode $-\mathrm{m}_{\mathrm{fi}}^{\mathrm{tf}}$ from the base values $-\mathrm{m}_{\mathrm{fi}}^{\mathrm{tf}}$,

$r_{m f i}=\left(m_{f i}^{t f 0} / m_{f}^{t+0}\right) \cdot 100 \%$ are the relative shares of $m_{f i}^{t f}$ in the total mass of $m_{f^{t}}^{t+0}$

To determine the values of $\delta \mathrm{m}_{\mathrm{fi}}^{\mathrm{tf}}$, experimental dependences are used, whose appearance is chosenis taking into account the results of previous studies (see Fig. 3):

$$
\delta m_{f i}^{t f}=k_{t f i}\left(\bar{n}_{i}, \bar{L}_{i}\right) \cdot\left(t_{f i}-t_{f 0 i}\right),
$$

where $k_{t f i}\left(\bar{n}_{i}, \bar{L}_{i}\right)$ - the proportionality factor, which is a function of the relative number of revolutions $-\bar{n}_{i}$ and load $-\bar{L}_{i}$;

Values $\bar{n}_{i}$ and $\bar{L}_{i}$ characterize the mode of operation of the engine and are determined by the following:

$$
\bar{n}_{i}=\frac{n_{i}-n_{\text {idle }}}{n_{\text {nom }}-n_{\text {idle }}}
$$

where $n_{\text {idle }}$ and $n_{\text {nom }}$ - the number of revolutions on idle move and mode rated power;

$$
\bar{L}_{i}=\frac{M_{k i}}{M_{k(\max ) i}},
$$

$\mathrm{M}_{\mathrm{k}(\max ) \mathrm{i}}$ - the maximum torque on the motor shaft at $\mathrm{n}_{\mathrm{i}}$. 


\subsection{Experimental installation and methods for investigating methodological error $\delta$ PTtf}

To determine the coefficients ktfi, used in the calculation of methodological error $\delta \mathrm{PTtf}$, an experimental setup and a methodology for its determination have been developed.

Schematic diagram of the experimental setup, its specifications (Figure 5).

The installation includes two main elements:

1) two-channel PM sampling line, which includes the control channel (it gathers mass $\mathrm{PM}-\mathrm{m}_{1}$ ) and the heated channel it collects the mass of $\mathrm{PM}-\mathrm{m}_{2}$, at a temperature $\mathrm{t}_{\mathrm{f}}$, more than in control channel, fixed value $\Delta \mathrm{t}_{\mathrm{f}}$; this equipment is designed to measure the $\mathrm{k}_{\mathrm{tf}}$ coefficient in any engine operating mode;

2) a camera for stabilization and weighing of filters, which is designed to determine the masses of the hanging $\mathrm{m}_{1}$ and $\mathrm{m}_{2}$.

When determining the $\mathrm{k}_{\mathrm{tf}}$ coefficient in the PM sampling line, two conditions are met:

a) the sample temperature $t_{f 1}$ in the heated channel exceeds the corresponding sample temperature $\mathrm{t}_{\mathrm{f} 2}$ in the control channel by magnitude by $\Delta \mathrm{t}_{\mathrm{f}}=20 \pm 0.5^{\circ} \mathrm{C}$ (provided by heater 2);

b) the mass flow rates of the diluted EG samples in both channels created by the gas blower 6 are kept constant with an error of $\pm 2 \%$ (by maintaining the temperature equal to $t_{p 1}$ and $t_{p 2}$ and zero pressure drop between flowmeters 5 with normal nozzles).

To determine the $\mathrm{k}_{\mathrm{tf}}$ coefficient, the dependence is used:

$$
k_{t f}=\frac{m_{2}-m_{1}}{m_{1} \cdot \Delta t_{f}} \cdot 100 \%=\frac{\delta m_{f}}{20}, \% \cdot\left({ }^{\circ} \mathrm{C}\right)^{-1},
$$

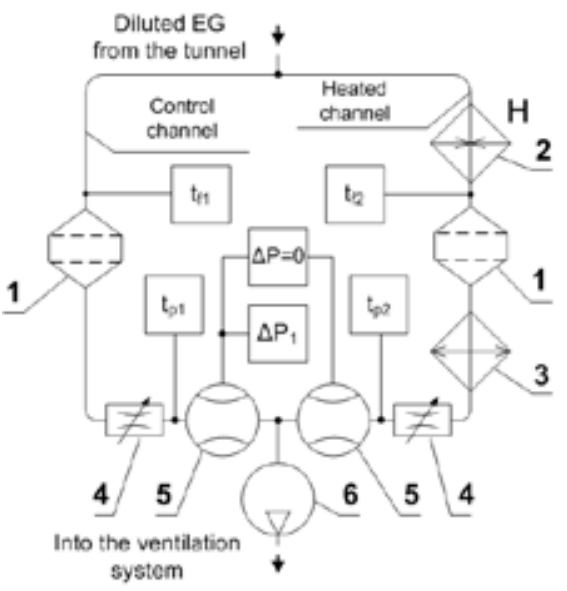

Figure 5. Experimental setup for measuring ktfi coefficients: 1 - ammunition with a filter; 2 heater; 3 - cooler; 4 - regulators of mass flow rates; 5 - mass flowmeters; 6 - gas blower 
where $\delta \mathrm{m}_{\mathrm{f}}-$ the relative deviation of the mass PM caused by temperature rise $t_{\mathrm{f}}$.

The relative error of determining the coefficients of $\mathrm{k}_{\mathrm{tf}}$ is $\pm 7 \ldots 12 \%$, while the greater value of the error corresponds to modes with low engine load.

Methodology of studies of the effect of temperature mode selection prob PM to the weight of the hinge PM. This method can be experimentally determined by the dependence of the diesel engine on the proportionality coefficients $\mathrm{k}_{\mathrm{tfi}}$, which take into account the effect of the temperature $\mathrm{t}_{\mathrm{f}}$ on the PM sample weight (see formula (12)) and used in determining errors $\delta \mathrm{PT}$ (see formula (11)). The determined dependence has the form $-k_{t i f}\left(\bar{n}_{i}, \bar{L}_{i}\right)^{\mathrm{tf}}$, where $\bar{n}_{i}$ and $\bar{L}_{i}$ - the parameters that characterize the test mode (see formulas (13), (14)).

Before starting the experiment, the normalization of variables $\bar{n}$ and $\bar{L}$ :

$$
\begin{aligned}
& X_{1}=\frac{\bar{n}-\bar{n}_{\text {mid }}}{\Delta \bar{n}} ; \\
& X_{2}=\frac{\bar{L}-\bar{L}_{\text {mid }}}{\Delta \bar{L}},
\end{aligned}
$$

where $\bar{n}_{\text {mid }}=\bar{L}_{\text {mid }}=0,5$ - the average values of the ranges of variation, $\bar{n}, \bar{L}$;

$\overline{\varnothing \bar{n}}=\left(\mathrm{n}_{\text {nom }}-\mathrm{n}_{\text {idle }}\right) / 4 ; \varnothing \bar{L}=\mathrm{M}_{\mathrm{k}(\max )} / 4-$ steps for changing parameters $\bar{n}$ and $\bar{L}$.

It is assumed that the dependence of the coefficient $\mathrm{k}_{\mathrm{tf}}$ on the variables $\mathrm{X}_{1}$

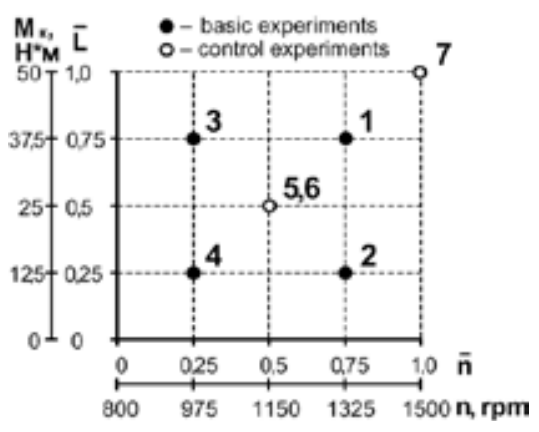

Figure 6. Plan of 2-factor experiment for determination of polynomial (15) and $\mathrm{X}_{2}$ has the form of a polynomial of the 1-st degree:

$$
k_{t f}=a_{0}+a_{1} \cdot X_{1}+a_{2} \cdot X_{2}
$$

where $\mathrm{a}_{0}, \mathrm{a}_{1}$ and $\mathrm{a}_{2}-$ constant coefficients.

To determine the coefficients of the polynomial and evaluate its accuracy, a 2-factor experiment is conducted, consisting of 4 basic and 3 control investigation (Figure 6).

The coefficients of regression dependence (15) are determined by the expressions [15]: 


$$
\begin{aligned}
& a_{0}=\frac{k_{t f 1}+k_{t f 2}+k_{t f 3}+k_{t f 4}}{4} \\
& a_{1}=\frac{k_{t f 1}+k_{t f 2}-k_{t f 3}-k_{t f 4}}{4} ; \\
& a_{2}=\frac{k_{t f 1}-k_{t f 2}+k_{t f 3}-k_{t f 4}}{4},
\end{aligned}
$$

where $\mathrm{k}_{\mathrm{tf}}$ - the value of the $\mathrm{k}_{\mathrm{t}}$, coefficient determined in the $\mathrm{i}$-th investigation. The adequacy of this dependence is estimated by the Fisher criterion $-\mathrm{F}$.

\subsection{Methods for estimating the resulting error $\delta P T$ and the effectiveness of recommendations to reduce it}

The resulting measurement error of the weighted average PM with EG emission from the diesel engine diesel and the effectiveness of the recommendations for its reduction are estimated by the following algorithm.

1. Selection of initial data for research - the results of tests of diesel on the ESC cycle, indicating all the parameters that affect the accuracy of measurements of the PT (error $\delta \mathrm{PT}$ ).

2. For each dilution mode EG, instrumental measurement errors of the weighted average $\mathrm{PM}-\delta \mathrm{PT}_{\text {in }}$ emission are determined by successive calculations using the expression (10) of the error values calculated by formulas (1) - (6).

3 . The ranges of variation of the method error $\delta \mathrm{PT}_{\mathrm{tf}}$; are established (taking into account the mode of dilution of EG); to this end, the expressions (11) and the method of planning the 2-factor experiment [15] are determined by

$$
\delta \mathrm{PT}_{\mathrm{tf}}=\mathrm{f}\left(\mathrm{t}_{\mathrm{dil}}, \mathrm{t}_{\mathrm{f}(\max )}\right)
$$

with the domain of the function $\mathrm{t}_{\mathrm{dil}}=20 \ldots 30^{\circ} \mathrm{C}, \mathrm{t}_{\mathrm{f}(\max )}=42 \ldots .52^{\circ} \mathrm{C}$;

The absolute deviations of the value $\delta \mathrm{PT}_{\mathrm{t}}$, calculated by dependence (16) from the values calculated by formula (11) shall not exceed $\pm 0,05 \%$.

4. Installed: the variation range of the resulting error $\delta \mathrm{PT}$ (by expression (9)), as well as the value of the width of the variation range of the given error $-\delta \mathrm{PT}^{\text {sum }}$ and its components $-\delta \mathrm{PT}_{\mathrm{j}}^{\text {sum: }}$

$$
\delta P T^{\text {sum }}=\delta P T^{+}-\delta P T^{-} ; \delta P T_{j}^{\text {sum }}=\delta P T_{j}^{+}-\delta P T_{j}^{-},
$$

where the indices «+»» and «-») correspond to the limit values of the ranges of variation of the corresponding errors in the area of positive and negative values;

$j$ - the index of the component of the resulting error (in or $t_{f}$ ). 
5. Determine the relative contribution (in \%) to the resulting error $\delta \mathrm{PT}$ of each component $-\mathrm{R}_{\mathrm{j}}$ :

$$
R_{j}=\frac{\delta P T_{j}^{\text {sum }}}{\delta P T^{\text {sum }}} \cdot 100 \% .
$$

6. Calculations of the error $\delta \mathrm{PT}$ and its components are carried out, provided that the proposed recommendations for improving the efficiency of determining the PT indicator are fulfilled.

\section{Results of experimental and computational studies of the accuracy of the gravimetric PM control method}

\subsection{Determination of instrumental error of PT measurements}

As a result of applying dependence (9) to the values measured indirectly, formulas were calculated to calculate the error $\delta \mathrm{PT}$ in and its maximum values for different modes of dilution of EG (Table 3).

Table 3

The results of determining the instrumental error $\delta$ PTin

\begin{tabular}{|c|c|c|c|}
\hline \multirow{2}{*}{ Error } & \multirow{2}{*}{$\begin{array}{l}\text { Expression to calculate } \\
\text { the error }\end{array}$} & \multicolumn{2}{|c|}{ The error value, $\%$} \\
\hline & & DM1 & DM2 \\
\hline$\delta G_{\text {edf }(m)}$ & $\sqrt{\sum_{i=1}^{13}\left(W F_{i} \cdot k_{\text {Gedfi }} \cdot \delta G_{\text {edf } i}\right)^{2}}$ & 1,4 & 1,1 \\
\hline$\delta \mathrm{PT}$ mass & $\sqrt{\delta M_{f}^{2}+\delta M_{s a m}^{2}+\left(\delta G_{e d f(m)}\right)^{2}}$ & 4,4 & 3,1 \\
\hline$\delta \mathrm{P}_{\mathrm{i}}$ & $\sqrt{\delta n^{2}+\delta M_{k}^{2}}$ & 3,6 & 3,6 \\
\hline$\delta \overline{\mathrm{P}}$ & $\delta P_{i} \cdot \sqrt{\sum_{i=1}^{n}\left(W F_{i} \cdot k_{P_{i}}^{2)}\right)^{2}}$ & 1,2 & 1,2 \\
\hline$\delta \mathrm{PT}$ & $\sqrt{\delta P T_{\text {mass }}^{2}+(\delta \bar{P})^{2}}$ & 4,5 & 3,3 \\
\hline
\end{tabular}

\subsection{Establishment and evaluation of methodological error of PT meas-urements}

As a result of the procedure of studies of the effect of temperature selection mode PM on the weight of the PM presented in section 4.3, a 2 -factor experiment was conducted and the dependence of the $\mathrm{k}_{\mathrm{tf}}$ coef- 
ficient on the parameters of the engine operating mode was determined (Table 4, 5):

- when using normalized variables:

$$
k_{t f}=-0,996-0,037 \cdot X_{1}+0,138 \cdot X_{2} ;
$$

- in the transition from normalized to initial variables (Figure 7)

$$
k_{t f}=-1,20-0,148 \cdot \bar{n}+0,552 \cdot \bar{L} .
$$

Table 4

\begin{tabular}{|c|c|c|c|c|c|c|c|c|}
\hline \multirow{2}{*}{ № д } & \multicolumn{3}{|c|}{ Tunnel options } & \multicolumn{3}{|c|}{\begin{tabular}{|c|} 
PM selection options (in the \\
control channel)
\end{tabular}} & \multicolumn{2}{|c|}{ Results tests } \\
\hline & $\mathbf{G}_{\text {exh }}, \Gamma / c$ & $\mathbf{t}_{\mathrm{exh}},{ }^{\circ} \mathrm{C}$ & $\mathbf{q}$ & $\mathbf{t}_{\mathrm{f}},{ }^{\circ} \mathbf{C}$ & $\mathbf{m}_{\mathrm{f}}, \mathbf{M \Gamma}$ & $\begin{array}{l}\mathbf{P T _ { \text { mass } }} \\
\mathbf{\Gamma}, \mathbf{Y}\end{array}$ & $\Delta \mathbf{t}_{\mathrm{f}},{ }^{\circ} \mathbf{C}$ & $-\underset{\%}{\delta m_{f}}$ \\
\hline 1 & 18,6 & 310 & 5,12 & 45,2 & 4,4 & 15,2 & 19,7 & 19,5 \\
\hline 2 & 18,6 & 277 & 5,11 & 38,7 & 4,7 & 12,0 & 20,5 & 22,1 \\
\hline 3 & 13,7 & 231 & 6,93 & 34,0 & 3,9 & 10,3 & 20,2 & 14,7 \\
\hline 4 & 13,7 & 184 & 6,90 & 29,2 & 5,2 & 7,7 & 19,4 & 23,0 \\
\hline 5 & 16,1 & 252 & 5,92 & 35,5 & 4,3 & 11,5 & 20,0 & 19,2 \\
\hline 6 & 16,0 & 263 & 5,95 & 36,0 & 4,8 & 11,2 & 20,3 & 17,9 \\
\hline 7 & 20,9 & 347 & 4,54 & 51,9 & 5,8 & 17,2 & 20,2 & 15,2 \\
\hline
\end{tabular}

The results of the dependency experiment $k_{t i \hat{i}}\left(\bar{n}_{i}, \bar{L}_{i}\right)$

Table 5

Results of comparison of experimental $-k_{\mathrm{tf}}$ and calculated $-\mathbf{k}_{\mathrm{tfp}}$ data

\begin{tabular}{|c|c|c|c|c|c|}
\hline № $\boldsymbol{A}$ & $\mathbf{X}_{\mathbf{1}}(\overline{\boldsymbol{n}})$ & $\mathbf{X}_{\mathbf{2}}(\overline{\boldsymbol{L}})$ & $\mathbf{- k}_{\mathbf{t f}} \mathbf{1 0}^{-\mathbf{2}},{ }^{\circ} \mathbf{C}^{-\mathbf{1}}$ & $\mathbf{- k}_{\mathbf{t f p}} \cdot \mathbf{1 0}^{-\mathbf{2}},{ }^{\circ} \mathbf{C}^{-\mathbf{1}}$ & $\mathbf{\delta} \mathbf{k}_{\mathbf{t}}, \mathbf{\%}$ \\
\hline 1 & $1(0,75)$ & $1(0,75)$ & 0,99 & 0,90 & 9,3 \\
\hline 2 & $1(0,75)$ & $-1(0,25)$ & 1,08 & 1,17 & $-8,6$ \\
\hline 3 & $-1(0,25)$ & $1(0,75)$ & 0,73 & 0,82 & $-12,7$ \\
\hline 4 & $-1(0,25)$ & $-1(0,25)$ & 1,19 & 1,10 & 7,8 \\
\hline $5,6^{*}$ & $0(0,5)$ & $0(0,5)$ & 0,92 & 1,00 & $-8,1$ \\
\hline 7 & $2(1,0)$ & $2(1,0)$ & 0,86 & 0,75 & 12,4 \\
\hline
\end{tabular}

Note: $*$ - the average result of 2 measurements

The validity of expression (17) is confirmed by the fact that the relative deviations of the calculated values of $\mathrm{k}_{\mathrm{tf}}$ from the experimental data are \pm $7.8 \ldots 12.7 \%$ (standard deviation calculated from the results of 2 duplicate investigation - the 5 th and 6 th equals $\pm 0,056$ or $4.7 \ldots 6.5 \%$ ) and are values of the same order with the error of the experiment $- \pm 3 \ldots 8 \%$. 


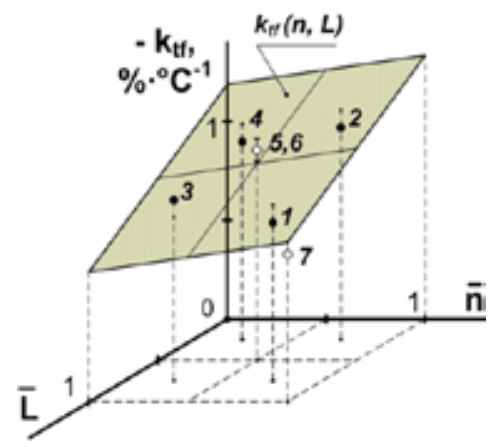

Figure 7. Results of experimental determination of dependence $k_{t f i}\left(\bar{n}_{i}, \bar{L}_{i}\right)$
Thus, the methodical error $\delta \mathrm{PT}$ tf can be estimated by the following formula (see expressions (11) and (12)):

$$
\begin{gathered}
\delta P T_{\text {tf }}=\sum_{i=1}^{13}\left(-1,20-0,148 \cdot \bar{n}_{i}+0,552 \cdot \bar{L}_{i}\right) . \\
\cdot\left(t_{f i}-t_{f 0 i}\right) \cdot r_{m f i} .
\end{gathered}
$$

The estimation of the value $\delta \mathrm{PT}_{\mathrm{tf}}$, carried out on the results of the tests of diesel $1 \mathrm{Ch} 12 / 14$ on the ESC cycle, shows that the ranges of variation of this error are: $-4.5 \ldots$ $6.3 \%$ (difference of results $-10.8 \%$ ) (Figure 8).

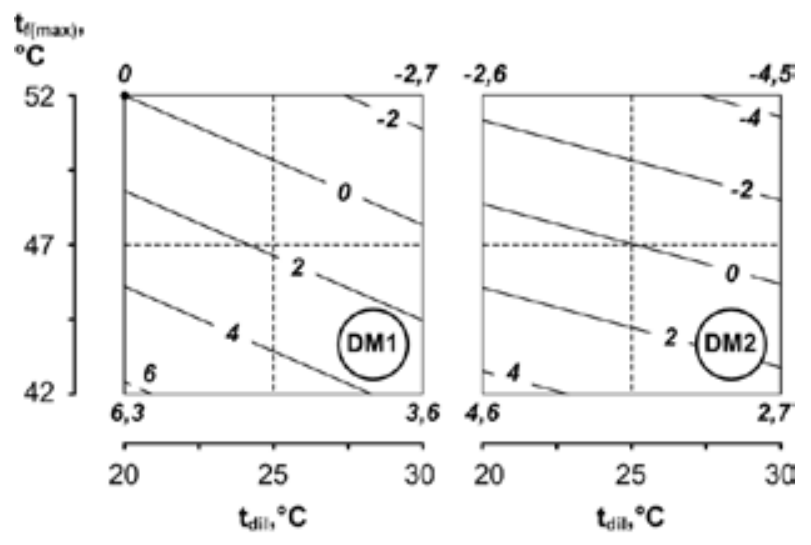

Figure 8. The range of variation of the method error $\delta P T t f$

\subsection{Evaluation of the error $\delta P T$, the significance of its components and the effectiveness of the recommendations developed}

In accordance with the methodology described in paragraph 4.4 , the calculated studies were conducted, during which the ranges of variation of the instrumental $\delta \mathrm{PT}_{\mathrm{in}}$, the methodical $\delta \mathrm{PT}_{\mathrm{tf}}$, and the resulting $\delta \mathrm{PT}$ errors in the measurements of the indicator PT. In the course of the research, the relative contributions to the error $\delta \mathrm{PT}$ of each of its components $\mathrm{R}_{\mathrm{j}}$, were 
evaluated, it was determined how the value of $\delta \mathrm{PT}$ and its components changes when making the recommendations made to improve the efficiency of measuring the value of PT.

The research results indicate the following:

- the components of the resulting measurement error of the PT index vary in the ranges:

a) subject to ISO 8178 standards carrying out tests:

$$
\delta \mathrm{PT}_{\text {in }}= \pm 3.3 \ldots \pm 4.5 \%, \delta \mathrm{PT}_{\mathrm{tf}}=-4.5 \ldots 6.3 \% \text {; }
$$

b) when conducting tests in the light of the recommendations made to improve the efficiency of determining the PT indicator:

$$
\delta \mathrm{PT}_{\text {in }}= \pm 3.3 \%, \delta \mathrm{PT}_{\text {tf }}=0 \% ;
$$

- when allowed dilution modes of EG, the resulting error $\delta \mathrm{PT}$ varies in the range $-9.0 \ldots 10.8 \%$ ( $19.8 \%$ difference in results); the largest contribution to $\delta \mathrm{PT}$ is made by the methodological component $-55 \%$; contribution of instrumental component $-45 \%$;

- as a result of the implementation of the proposed recommendations, the resulting error $\delta \mathrm{PT}$ is reduced to $\pm 3.3 \%$ (the divergence of results of $6.6 \%$ is reduced by 3 times); with the contribution of the instrumental component in $\delta \mathrm{PT}$ increases to $100 \%$.

\section{Conclusions}

Based on the analysis of requirements of regulatory documents international standard ISO 8178, UNECE Regulations R-83, R-49, R-96 and others to the conditions of operation of mass emission control PM with EG diesel engines - tunnels, as well as world and own experience of using tunnels, recommendations are made to improve the accuracy of gravimetric method of PM control:

1) ensuring that the maximum possible mass of $P M$ is sampled by the filter by maintaining the dilution coefficient of EG with air in the tunnel at the minimum permissible level $-\mathrm{q}=4$;

2) elimination of methodological errors of measurements of mass emission of PM, which depend on temperature conditions of sampling of $\mathrm{PM}$, due to the use of sample temperature regulators in the tunnels;

3) improving the accuracy of measurement values used in determining the average operating PM emission - PT. 
A scientific and practical basis for conducting studies of the accuracy of gravimetric measurements of PM is created, which consists of: a mathematical model for determining the temperature conditions of sampling in tunnels, a mathematical model for evaluating the resulting error in the measurements of the metric $\mathrm{PT}-\delta \mathrm{PT}$; experimental setup and research methodology to determine the methodological error of the $\mathrm{PT}-\delta \mathrm{PT}_{\mathrm{tf}}$ measurement, which depends on the temperature conditions of sampling in the tunnel; the method of estimating the significance of the components of the resultant error in the measurements of the PT index: instrumental $\delta \mathrm{PT}_{\text {in }}$ and methodical errors.

Experimental and computational studies of the accuracy of the gravimetric PM control method, which meets the requirements of the international standard ISO 8178, average operational emissions PM when using this method: $\delta \mathrm{PT}_{\text {in }}= \pm 3.3 \ldots \pm 4.5 \% ; \delta \mathrm{PT}$ tf $=-4.5 \ldots 6.3 \% ; \delta \mathrm{PT}=$ $-9.0 \ldots 10.8 \%$. The effectiveness of the recommendations made by the authors is confirmed and it is established that their implementation allows to increase the accuracy of the gravimetric method of PM control by 3 times by eliminating the error $\delta \mathrm{PT}$ tf and reducing the value of $\delta \mathrm{PT}$ to the minimum level of instrumental error $\pm 3.3 \%$.

\section{References:}

1. Foote E. (2013). Evaluation of Partial Flow Dilution Methodology for Light Duty Particulate Mass Measurement. SAE Technical Paper 2013-01-1567, 10.

2. Perez J., Lipari F. \& Seizinger D. (1984). Cooperative development of analytical methods for diesel emissions and particulates // SAE Technical Papers, 840413, 22.

3. Russel R. (1993). Development of a Miniaturized, Dilution-Based Diesel Engine Particulate Sampling System for Gravimetric Measurement of Particulates. SAE Technical Papers, 931190, 12.

4. Klimenko O. \& Redziuk A. (2012). Research and development of a promising system for determining the mass emissions of pollutants in the exhaust gases of engines [in Ukrainian]. Avtoshlyahovik Ukraine, 5(229), 2-8.

5. Engeljehringer K. (1993). Meeting ISO 8178 Requirements for the Measurement of Diesel Particulates with Partial-Flow Dilution Systems. SAE Technical Papers, 932466, 10.

6. Nagano H. (1990). Measurement of Unregulated Exhaust Emissions from Heavy Duty Diesel Engines with Mini-Dilution Tunnel. SAE Technical Papers, 900643, 10.

7. Lach G. (1988). Specific problems of sampling and measuring diesel exhaust emissions. SAE Technical Papers 881763, 12. 
8. Redziuk A., Klimenko O. \& Kudlenko O. (2012). With respect to the determination of the mass emissions of pollutants by wheeled vehicle engines. Avtoshlyahovik Ukraine, 4(228), 2-7. (in Ukrainian)

9. Polivyanchuk A. (2015). Improving the efficiency of diesel particulate emissions control systems: monograph [in Ukrainian]. Publisher KNAHU, Kharkiv, 220.

10. Hirakouchi N. (1989). Measurement of Diesel Exhaust Emissions with Mini-Dilution Tunnel. SAE Technical Papers, 890181, 11.

11. Bolgarsky A.V. \& Mukhachev G.A. (1964). Thermodynamics and heat transfer. Higher school, 458. (in Russian)

12. Polivyanchuk A. (2015). Experimental verification of microtunnel MKT-2 on the brake stand autotractor diesel engine. Industrial technology and engineering, 2(15), 11-16.

13. Himmelblau D. (1973). Analysis of processes by statistical methods. World, 957. (in Russian)

14. Novinsky P. \& Zograph I. (1985). Estimation of errors of measurement results. Energoatomizdat, St Petersburg, 248. (in Russian)

15. Rafales-Lamarca E. (1969). Experiment Planning Instructions. Ukrainian Design and Research Institute «UkrNIIugleobogashenie», Lugansk, 126. 